\title{
BMJ Open Impact of the COVID-19 pandemic on asthma control among children: a qualitative study from caregivers' perspectives and experiences
}

\author{
Yuanmin Jia (D) , ${ }^{1}$ Jingxian Bao, ${ }^{1,2}$ Mo Yi, ${ }^{1}$ Zeyi Zhang, ${ }^{1}$ Jingjing Wang, ${ }^{1}$ \\ Haixia Wang, ${ }^{1}$ Yizhang $\mathrm{Li}^{1}{ }^{1}$ Ou Chen ${ }^{1}$
}

To cite: Jia Y, Bao J, Yi M, et al. Impact of the COVID-19 pandemic on asthma control among children: a qualitative study from caregivers' perspectives and experiences. BMJ Open 2021;11:e046525. doi:10.1136/ bmjopen-2020-046525

- Prepublication history and supplemental material for this paper is available online. To view these files, please visit the journal online (http://dx.doi org/10.1136/bmjopen-2020046525).

Received 04 November 2020 Revised 29 March 2021 Accepted 08 April 2021
Check for updates

(c) Author(s) (or their employer(s)) 2021. Re-use permitted under CC BY-NC. No commercial re-use. See rights and permissions. Published by BMJ.

${ }^{1}$ School of Nursing and Rehabilitation, Cheeloo College of Medicine, Shandong University, Jinan, China ${ }^{2}$ Department of Pediatric Respiratory, Shandong Provincial Hospital Affiliated to Shandong First Medical University, Jinan, China

Correspondence to

Dr Ou Chen;

chenou@sdu.edu.cn

\section{ABSTRACT}

Objectives To understand the impact of the COVID-19 epidemic on asthma control in children based on caregivers' perspectives and experiences.

Design This was a qualitative study deploying face-toface, semistructured interviews. Thematic analysis was carried out to analyse the data.

Setting Paediatric respiratory clinics in three tertiary hospitals.

Participants 16 caregivers providing unpaid asthmarelated care and assistance to children under 14 years who had been diagnosed with asthma for more than 1 year and were not only treated with short-acting $\beta 2$-agonists.

Results Six main themes were identified: (1) improved asthma control; (2) decreased willingness to seek medical care driven by fear; (3) increased adherence due to enhanced awareness of asthma control; (4) coping strategies for changes caused by COVID-19; (5) a new opportunity and (6) managing new challenges in asthma control.

Conclusions The COVID-19 outbreak and the measures in response to it have had significant impacts on asthma control among children. Children with asthma are advised to continue good asthma management, take their prescribed asthma medications as normal, wash their hands regularly and wear face masks. Regularly supported self-management and remote consultations should be provided during the COVID-19 pandemic. In addition, supporting people financially, providing continued medical support and alleviating any fear and anxiety should be considered. We anticipate that our findings will inform health promotion interventions.

\section{BACKGROUND}

COVID-19, which is associated with significant morbidity and medical complications induced by SARS-CoV-2, has rapidly spread sparking alarm worldwide. ${ }^{1}$ The $\mathrm{WHO}$ declared this outbreak a pandemic on 11 March 2020. ${ }^{2}$ COVID-19 has infected over 100 million people and resulted in 2776175 deaths across 235 countries globally as of 29 March 2021. ${ }^{3}$
Strengths and limitations of this study

- This was a qualitative study using open questions and prompts to explore the impact of COVID-19 on asthma control in children in more depth.

- Face-to-face, semistructured interviews conducted by an experienced researcher allowed in-depth analysis of the perspectives and experiences of caregivers, complementing the findings of quantitative studies.

- To our knowledge, this article is the first of its kind.

- The findings might be generalisable to children with mild-to-moderate asthma.

- The perspectives and experiences of caregivers may change over time as the nature of the outbreak is fluctuating.

The COVID-19 virus outbreak has had farreaching implications on health, society and the economy. ${ }^{4-6}$ To contain and mitigate the spread of COVID-19, governments around the world have initiated a series of political and public health measures, such as regular hand hygiene, using masks, quarantines, lockdowns and social distancing. ${ }^{47-10}$ In addition, providing remote consultations, modifying usual care and avoiding carrying out bronchoscopy and most pulmonary function tests where possible are recommended in the National Institute for Clinical Excellence (NICE) COVID-19 Severe Asthma Rapid Guideline Update (NG166). ${ }^{9}$ Asthma is a chronic disease requiring long-term medical monitoring, and individuals with asthma are particularly vulnerable to the changes resulting from COVID-19. ${ }^{11}$ It was reported that the risk of severe illness and death from COVID-19 was increased for people with severe asthma and those prescribed highdose inhaled corticosteroids (ICS) ${ }^{9}{ }^{12-14}$ The COVID-19 outbreak and the measures in response to it have had significant impacts on 
people with long-term respiratory conditions including disruptions in healthcare provision, high levels of loneliness, anxiety and concerns regarding the impact of COVID-19. ${ }^{15} 16$ An online survey of caregivers of children with asthma from 27 countries and 5 continents revealed that during the COVID-19 pandemic, 47\% of asthmatic children reported limited access to healthcare services and $20 \%(10 \%-40 \%)$ reported better disease control. ${ }^{17}$ It was also reported that medication adherence among patients with asthma increased. ${ }^{17}{ }^{18}$ Furthermore, lockdown restrictions, school cancellations and social distancing have had important implications for movement and play behaviours, limiting children's physical activity (PA) and reducing exposure to environmental triggers. ${ }^{811}$ These changes in health-seeking behaviours, medication management and the environment may potentially impact asthma control. ${ }^{11}$ To develop effective public health strategies, it is crucial to understand how the changes resulting from COVID-19 have impacted asthma control among children, but this has not been fully determined.

Caregivers play an important role in the management of asthma. ${ }^{19}$ During the COVID-19 pandemic, children depend more on their caregivers, and thus, caregivers might have an increased responsibility for asthma control as a result of stay-at-home orders. ${ }^{6}$ Home quarantine and school cancellations have changed caregivers' daily routines and roles, resulting in increased stress and new challenges for caregivers in managing asthma in children. ${ }^{620}$ In the exploration of the impact of COVID-19 on asthma control in children, caregivers' perspectives and experiences cannot be overlooked, as they might influence asthma management behaviours and outcomes in children. $^{21} 22$

Thus, we conducted a qualitative study examining the perspectives and experiences of caregivers and what drives these using in-depth interviews; to our knowledge, this is the first study of its kind that will allow a better understanding of the impact of COVID-19 on asthma control in children. We anticipate that the findings will inform health promotion interventions to guide children and their caregivers to engage in effective asthma management during the outbreak.

\section{METHODS}

\section{Setting and participants}

Participants $(n=16)$ were purposively recruited from paediatric respiratory clinics in three tertiary hospitals in May 2020. Participants were selected if they provided unpaid asthma-related care and assistance to children under 14 years who had been diagnosed with asthma for more than 1 year and were not only treated with shortacting $\beta 2$-agonists. Caregivers and children with mental and cognitive impairment, organic psychosis or other cardiopulmonary diseases were excluded from this study. The participants provided written informed consent before starting the interviews.

\section{Data collection}

Face-to-face, semistructured interviews were conducted by an experienced researcher $(\mathrm{YJ})$ trained in qualitative interviewing methods and ethics. We interviewed caregivers about whether the children's asthma control statuses had changed, how the COVID-19 pandemic had impacted the children's asthma control, their own perspectives and experiences of asthma control and how they managed their children's asthma during the outbreak. The individual conversations (10-29 min) were audio-recorded and transcribed verbatim, and any identifying information was deleted. ${ }^{23}$ Field diaries with notes on alterations in speech and non-verbal communication were subsequently used to supplement the transcripts. Survey questionnaires were administered to assess asthma control (the Childhood Asthma Control Test (C-ACT) $)^{24}$ and collect sociodemographic data. Our interview followed a topic schedule to guide the discussion (see the online supplemental file 1), and open and flexible discussions on topics were also allowed. ${ }^{25} 26$

\section{Data analysis}

Data were analysed using NVivo V.11. We performed thematic analysis as proposed by Braun and Clarke ${ }^{27}$ to explore the associations (and contradictions) of the qualitative data for their further interpretation. ${ }^{28} 29$ The initial codes generated from the transcripts that were read repeatedly were developed into preliminary themes. The initial thematic framework was crosschecked with the raw data, and it was reviewed and refined through regular team debriefings to resolve differences and reach consensus. The data collection and analysis were conducted simultaneously until thematic saturation was reached, ${ }^{30}$ and the most relevant and specific topics were selected for presentation in this paper.

\section{RESULTS}

The caregivers $(\mathrm{n}=16)$ were all the parents of the children with asthma; 14 mothers aged $30-40$ years and 2 fathers aged 40-48 years participated in this study. The average age of the children was 8.0 years. The characteristics of the children and caregivers are summarised in table 1 . Six main themes were identified from the caregiver dataset.

\section{Improved asthma control}

In the subjective assessment of children's asthma control statuses, the majority of the caregivers reported that their children had mild or no symptoms and that the level of asthma control was maintained or even improved compared with that before the epidemic. Generally improved self-management, increased medication adherence, the use of masks and changes in asthma triggers due to lockdowns, such as decreased PA, fewer symptomatic colds and less exposure to outdoor allergens, might have contributed to the better-than-expected asthma control.

I perceive that my child's asthma is better controlled. He has milder asthma symptoms, probably because 
Table 1 Participant characteristics

\begin{tabular}{|c|c|c|c|c|c|}
\hline \multirow{3}{*}{ Characteristics } & & \multirow[b]{3}{*}{ Household } & \multirow{3}{*}{$\begin{array}{l}\text { Children }(n=16) \\
n(\%)\end{array}$} & \multicolumn{2}{|l|}{ Caregivers } \\
\hline & & & & Mothers $(n=14)$ & Fathers $(n=2)$ \\
\hline & & & & n (\%) & n (\%) \\
\hline Gender & Female & - & $7(43.75)$ & $14(87.50)$ & - \\
\hline \multirow[t]{5}{*}{ Age (years) } & $4-7$ & - & $6(37.50)$ & - & - \\
\hline & 30-35 & - & - & $4(25.00)$ & - \\
\hline & $36-40$ & - & - & $10(62.50)$ & $1(6.25)$ \\
\hline & $41-45$ & - & - & - & - \\
\hline & $46-50$ & - & - & - & $1(6.25)$ \\
\hline Place of residence & City & $12(75.00)$ & - & - & - \\
\hline \multirow[t]{4}{*}{ Annual household income } & Less than $¥ 30000$ & $2(12.50)$ & - & - & - \\
\hline & $¥ 30$ 000-¥80000 & $7(43.75)$ & - & - & - \\
\hline & $¥ 80000$ or more & $5(31.25)$ & - & - & - \\
\hline & No response given & $2(12.50)$ & - & - & - \\
\hline \multirow[t]{4}{*}{ Marital status } & Single & - & - & - & - \\
\hline & Cohabiting & - & - & - & - \\
\hline & Married & - & - & 14 (87.50) & 2 (12.5) \\
\hline & Separated & - & - & - & - \\
\hline C-ACT scores & $\geq 20$ (good control) & - & $8(50.00)$ & - & - \\
\hline
\end{tabular}

C-ACT, Childhood Asthma Control Test.

he stays at home every day with less exposure to outdoor air allergens and is less likely to catch a cold... He usually has an asthma attack when he has a cold... During the pandemic, he has not had a cold or asthma attacks. (C13)

It (asthma control) is better than before the outbreak...During the epidemic, she cannot exercise vigorously outdoors and has few opportunities for physical activity that could trigger an asthma attack... (C9, C-ACT 15)

\section{Decreased willingness to seek medical care driven by fear}

Nearly all caregivers reported that they were reluctant to seek healthcare if their children had mild asthma symptoms and that they did not visit the asthma clinic regularly, only if symptoms persisted and worsened. The caregivers expressed that they were unwilling to put themselves and their children at higher risk of exposure to the virus and feared being quarantined, which led to delayed hospital visits during the COVID-19 outbreak.

I must be afraid...I did not bring my child to the hospital during the epidemic. Normally, we would have a checkup every 3 months, but it has now been 6 months. I am afraid to go to the hospital. (C7, C-ACT 23)

I'm afraid that my child will contract the virus if we go to the hospital because I don't know who comes to the hospital and what virus they're carrying. That's what I'm most concerned about... Basically, if we have medicine at home, we don't go to the hospital unless my child has an acute attack and we can't handle it. (C4, C-ACT 17)

I worry about cross-infection of COVID-19 in the hospital, fearing that I might contract COVID-19 and transmit it to my child. (C16, C-ACT 20)

\section{Increased adherence due to enhanced awareness of asthma control}

The caregivers reported increased medication adherence. During the epidemic period, the caregivers strengthened their supervision of their children's medication management and urged them to take their medications as prescribed. The improved adherence in the children might have been driven by the caregivers' enhanced 
awareness of asthma control. The caregivers expressed that they had heightened concerns over their children's health and asthma control due to their worries about asthma attacks and symptoms such as fever, cough and cold during the COVID-19 outbreak.

My child did not take her medication consistently before the outbreak; she only took drugs when she had an asthma attack. Now she takes her medications on time...During the COVID-19 outbreak, I realized that the situation is quite serious and that the disease (asthma) is a respiratory disease that must be treated regularly. So, I supervise and remind her to take her medicine on time according to the doctor's advice. (C5, C-ACT 17)

...Don't have an asthma attack, don't catch a cold; this is what I worry about when I take care of my child at home. (C16, C-ACT 20)

\section{Coping strategies for changes caused by COVID-19}

Most participants reported alternative practical strategies for coping with the challenges of COVID-19 and they sought solutions and guidance to maintain normal asthma control during lockdown, such as virtual online or telephone consultations and home remedies.

\section{Increased consultations via phone call or video conferencing}

During the pandemic, due to isolation at home and fear of going to the hospital for medical treatment, the caregivers chose to access healthcare through virtual online or telephone consultations with professional doctors who had treated their children before and knew their conditions well to enable the continuation of treatment. Nevertheless, several caregivers had some concerns about virtual consultation and regarded it as a suboptimal clinical encounter in which doctors could not comprehensively assess their children's situations.

During the outbreak, I have been afraid of viruses in the external environment and have not dared to take my child to the hospital for further consultation...I made an appointment for an online clinic and consulted the doctor about how to decrease the medication dosage via video call... (C15, C-ACT 17)

A telephone consultation is not as good as a faceto-face meeting during which the doctor can assess children through inspection and auscultation...The source of information for the assessment is only my description of the child's condition via telephone calls... (C14, C-ACT 21)

\section{Increased attempts at home remedies}

The majority of the participants reported that they relied more on home remedies, preferring to treat their children at home rather than go to the hospital during the epidemic. The caregivers had reserves of medicines at home purchased from pharmacies using old prescriptions and they supervised their children in following their medication regimens and consulted a doctor if they had any questions during lockdown. The caregivers attempted to manage their children's asthma at home.

I have prepared the atomized medicine at home...I urge him to take the medicine according to the original medication regimen...If the medicines are not enough, I'll go to the pharmacy to buy some more... (C10, C-ACT 22)

\section{A new opportunity}

Interestingly, approximately half of the caregivers considered that home quarantine offered new opportunities to access more support for their children; they appreciated the increased time and energy that they could devote to asthma control due to the lockdown. Additionally, the caregivers reported that they had increased responsibility placed on them and that they managed their children's asthma more carefully and comprehensively during the COVID-19 pandemic.

During the outbreak, we have been quarantined at home, unlike in the past (before the outbreak) when I had to go to work... Now, I stay at home as a result of the lockdown and have more time to care for my children more carefully... (C14, C-ACT 21)

\section{Managing new challenges in asthma control}

Increased financial burdens due to lockdown

Several caregivers, especially those with low income, reported experiencing financial stress. Reduced work hours or job loss due to lockdown resulted in lower household incomes. Some caregivers said that they had trouble affording treatment and examination costs.

During the outbreak, my husband and I are both at home and do not go out to work; our incomes have been reduced...I do not have as much money to pay for treatment costs as before. (C16, C-ACT 20)

\section{Increased difficulties purchasing drugs}

A minority of the caregivers noted that some drugs at certain doses were not available in nearby pharmacies from which they preferred to buy medications during the COVID-19 outbreak.

During the outbreak, I bought medicines from the nearest pharmacy...It's just that some medicines cannot be purchased. (C9, C-ACT 15)

\section{DISCUSSION}

This study explored the impact of the COVID-19 epidemic on asthma control in children based on caregivers' perspectives and experiences. The findings revealed that the majority of the caregivers perceived that their children's level of asthma control was maintained or even improved during the epidemic. The maintenance or improvement of asthma control was probably partly 
mediated by increased medication adherence, which is critical to optimal asthma control, ${ }^{31}$ driven by enhanced awareness of asthma control and reduced exposure to asthma triggers, ${ }^{32}$ most notably respiratory infections, ${ }^{33}$ $\mathrm{PA}^{34}$ and outdoor allergens, ${ }^{35}$ due to the COVID-19 outbreak. These results indicated that even under the pressure of lockdown, children should continue good asthma management, adhere to medication treatments and avoid environmental triggers to control and prevent asthma symptoms and attacks. Better-than-expected asthma control was also reported by Papadopoulos et al. ${ }^{17}$ They conducted an online survey in 27 countries and 5 continents and reported that $20 \%(10 \%-40 \%)$ of children with asthma had improved asthma control with no apparent deterioration compared with that before the epidemic. Kaye $e t a l^{18}$ explored the changes in medication adherence among patients with asthma during the COVID-19 epidemic and reported a $14.5 \%$ increase in adherence. Lower PA levels were also observed in an online survey of 1472 children and youth, ${ }^{8}$ which means that children have less exposure to environmental triggers. These changes in medication management and the environment may potentially impact asthma control. ${ }^{11}$

The caregivers avoided face-to-face therapy for fear of potentially contracting COVID-19 and being quarantined (self or their children); instead, they accessed healthcare through virtual online or telephone consultations to seek guidance and solutions and proactively attempted home remedies. These approaches resulted in delayed hospital visits but enabled access to continued medical support and effective asthma management. Nevertheless, several caregivers regarded virtual consultations as suboptimal clinical encounters. Mobile consultation using phones in response to the COVID-19 outbreak was also highlighted by a previous study ${ }^{36}$ exploring the impact of the societal response to COVID-19 on access to healthcare. They reported that some residents and health workers used telephones for medical services to avoid physical access.

Some caregivers expressed that they had new opportunities to provide more support for their children by spending more time and energy on asthma control and managing new challenges, including increased financial burdens and difficulties purchasing drugs. Additionally, the caregivers noted their increased responsibility for taking care of their children, as also reported in a study ${ }^{6}$ exploring how COVID-19 and lockdown have affected the lives of patients with anorexia nervosa and their carers.

Our study also found that asthma control in children who closely followed daily medication regimens before the epidemic and reserved controller medication in advance was less affected by the epidemic. This finding reminds us that children with asthma should adhere to daily medication therapy at the ordinary times, especially during the COVID-19 outbreak, which can decrease the risk of respiratory exacerbations and improve asthma outcomes, ${ }^{37-39}$ and that they should reserve medicines in advance according to doctors' prescriptions to cope with the challenges of COVID-19.

\section{Strengths and limitations}

We conducted this qualitative study using four open questions and prompts that enabled the researchers to respect and follow the caregivers' logics and explore the impact of COVID-19 on asthma control in children in more depth. Our results provide an early understanding of potential reasons underlying the changes in asthma control due to COVID-19 and lockdown. There are also limitations that should be considered: the findings might be generalisable to children with mild-to-moderate asthma but not to the most severely unwell children since only two caregivers of children with severe asthma were recruited in this study. In addition, the number of participants is small. However, the findings reflect diverse perspectives and experiences of caregivers, and thematic saturation was reached. Therefore, we call for more qualitative studies of a larger number of participants with mild-to-severe symptoms of asthma to comprehensively explore the impact of the COVID-19 epidemic on asthma control in children.

\section{Clinical implications}

Our findings suggest that it is essential for patients to continue good asthma management during the outbreak. Children with asthma are advised to continue taking their prescribed asthma medications as normal, wash their hands regularly and wear face masks to decrease the risk of exacerbations. ${ }^{9} 1040$ To develop the self-management skills of children with asthma and their caregivers, regularly supported self-management comprising a written personalised asthma action plan telling the patient how to recognise and act on worsening asthma and regular review of skills, treatment and asthma control by health professionals should be provided during the COVID-19 pandemic, as recommended in the Global Initiative for Asthma report $2020^{10}$ and the guidelines of the British Thoracic Society/Scottish Intercollegiate Guideline Network 2019. ${ }^{41} 42$

In addition, strengthening the advertising and education about healthcare services provision in terms of who needs to continue healthcare seeking and what services are available is necessary and can be carried out through radio broadcasts, information hotlines and social media. Remote consultations via phone call or video conferencing, which can reduce face-to-face contact and enable continued medical support, appear essential in this context. Social, professional and psychosocial support focusing on supporting people financially, providing continued medical support and alleviating any fear and anxiety that is delivered remotely should be considered. We also recommend that children with asthma closely follow their daily medication regimens at all times, but especially during the COVID-19 outbreak, and prepare medicines in advance according to doctors' prescriptions.

\section{CONCLUSION}

Our study offers unique insight into how the changes resulting from COVID-19 have impacted asthma control among children. In general, the findings suggest that 
increased medication adherence driven by enhanced awareness of asthma control and reduced exposure to asthma triggers, most notably respiratory infections, PA and outdoor allergens, due to the COVID-19 outbreak might result in improved asthma control. During the pandemic, the caregivers in this study were reluctant to visit hospitals for fear of potentially contracting COVID-19 and being quarantined (self or their children), and they preferred to access healthcare through virtual online or telephone consultations and proactively attempted home remedies. The caregivers also expressed that they faced new opportunities to provide more support for their children and managed new challenges, including increased financial burdens and difficulties in drug purchasing. We anticipate that our findings will inform health promotion interventions to guide children and their caregivers to restore, maintain and promote effective asthma management during the outbreak.

Acknowledgements The authors acknowledge all the participants for taking the time to complete the semistructured interviews.

Contributors YJ, JB, MY and ZZ designed the study and collected the data. YJ, $\mathrm{JB}, \mathrm{JW}$ and $\mathrm{HW}$ analysed the data. YJ, JW, HW and YL wrote the manuscript. OC made manuscript revisions. All authors reviewed the results and approved the final version of the manuscript.

Funding This work was supported by the Key Research and Development Program of Shandong Province (Grant No. 2019GSF108198), the Natural Science Foundation of Shandong Province (ZR2020MH006) and the Humanities and Social Sciences Youth Team Project of Shandong University (Grant Nos IFYT1811, IFYT18036 and IFYT18037). The funding bodies were not involved in the design of the study, the collection, analysis and interpretation of data and the preparation of the manuscript.

Competing interests None declared.

Patient consent for publication Not required.

Ethics approval The study was approved by the Ethics Committee of Nursing and Rehabilitation College of Shandong University (Project ID: 2020—R—42).

Provenance and peer review Not commissioned; externally peer reviewed.

Data availability statement All data relevant to the study are included in the article or uploaded as supplemental information. No additional data are available.

Supplemental material This content has been supplied by the author(s). It has not been vetted by BMJ Publishing Group Limited (BMJ) and may not have been peer-reviewed. Any opinions or recommendations discussed are solely those of the author(s) and are not endorsed by BMJ. BMJ disclaims all liability and responsibility arising from any reliance placed on the content. Where the content includes any translated material, BMJ does not warrant the accuracy and reliability of the translations (including but not limited to local regulations, clinical guidelines, terminology, drug names and drug dosages), and is not responsible for any error and/or omissions arising from translation and adaptation or otherwise.

Open access This is an open access article distributed in accordance with the Creative Commons Attribution Non Commercial (CC BY-NC 4.0) license, which permits others to distribute, remix, adapt, build upon this work non-commercially, and license their derivative works on different terms, provided the original work is properly cited, appropriate credit is given, any changes made indicated, and the use is non-commercial. See: http://creativecommons.org/licenses/by-nc/4.0/.

ORCID iD

Yuanmin Jia http://orcid.org/0000-0003-2787-0156

\section{REFERENCES}

1 Lai C-C, Shih T-P, Ko W-C, et al. Severe acute respiratory syndrome coronavirus 2 (SARS-CoV-2) and coronavirus disease-2019 (COVID-19): the epidemic and the challenges. Int J Antimicrob Agents 2020;55:105924.
2 World Health Organization. Coronavirus disease (COVID-19) pandemic: WHO characterizes COVID-19 as a pandemic, 2020. Available: https://www.who.int/emergencies/diseases/novelcoronavirus-2019/events-as-they-happen

3 World Health Organisation. Coronavirus disease (COVID-19) outbreak situation, 2020. Available: https://www.who.int/emergencies/ diseases/novel-coronavirus-2019

4 Pietrobelli A, Pecoraro L, Ferruzzi A, et al. Effects of COVID-19 Lockdown on lifestyle behaviors in children with obesity living in Verona, Italy: a longitudinal study. Obesity 2020;28:1382-5.

5 Wilkinson A, Ali $\mathrm{H}$, Bedford J, et al. Local response in health emergencies: key considerations for addressing the COVID-19 pandemic in informal urban settlements. Environ Urban 2020;32:503-22.

6 Clark Bryan D, Macdonald P, Ambwani S, et al. Exploring the ways in which COVID-19 and lockdown has affected the lives of adult patients with anorexia nervosa and their carers. Eur Eat Disord Rev 2020;28:826-35.

7 Sethi BA, Sethi A, Ali S, et al. Impact of coronavirus disease (COVID-19) pandemic on health professionals. Pak J Med Sci 2020;36:S6-11.

8 Moore SA, Faulkner G, Rhodes RE, et al. Impact of the COVID-19 virus outbreak on movement and play behaviours of Canadian children and youth: a national survey. Int J Behav Nutr Phys Act 2020;17:85

9 National Institute for Clinical Excellence. COVID-19 rapid guideline: severe asthma, 2020. Available: https://www.nice.org.uk/guidance/ ng166

10 Global Initiative for Asthma. Global strategy for asthma management and prevention 2020: interim guidance on asthma management during the COVID-19 pandemic, 2020. Available: https://ginasthma org/wp-content/uploads/2020/04/GINA-2020-full-report_-final-_wms. pdf

11 Oreskovic NM, Kinane TB, Aryee E, et al. The unexpected risks of COVID-19 on asthma control in children. J Allergy Clin Immunol Pract 2020;8:2489-91.

12 Bloom Cl, Drake TM, Docherty AB, et al. Risk of adverse outcomes in patients with underlying respiratory conditions admitted to hospital with COVID-19: a national, multicentre prospective cohort study using the ISARIC who clinical characterisation protocol UK. Lancet Respir Med 2021. doi:10.1016/S2213-2600(21)00013-8. [Epub ahead of print: 04 Mar 2021].

13 Schultze A, Walker AJ, MacKenna B, et al. Risk of COVID-19-related death among patients with chronic obstructive pulmonary disease or asthma prescribed inhaled corticosteroids: an observational cohort study using the OpenSAFELY platform. Lancet Respir Med 2020;8:1106-20.

14 Williamson EJ, Walker AJ, Bhaskaran K, et al. Factors associated with COVID-19-related death using OpenSAFELY. Nature 2020;584:430-6.

15 Philip K, Cumella A, Farrington-Douglas J, et al. Respiratory patient experience of measures to reduce risk of COVID-19: findings from a descriptive cross-sectional UK wide survey. BMJ Open 2020;10:e040951.

16 Philip KEJ, Lonergan B, Cumella A, et al. COVID-19 related concerns of people with long-term respiratory conditions: a qualitative study. BMC Pulm Med 2020;20:319.

17 Papadopoulos NG, Custovic A, Deschildre A, et al. Impact of COVID-19 on pediatric asthma: practice adjustments and disease burden. J Allergy Clin Immunol Pract 2020;8:2592-9.

18 Kaye L, Theye B, Smeenk I, et al. Changes in medication adherence among patients with asthma and COPD during the COVID-19 pandemic. J Allergy Clin Immunol Pract 2020;8:2384-5.

19 Fawcett R, Porritt K, Stern C, et al. Experiences of parents and carers in managing asthma in children: a qualitative systematic review. JBI Database System Rev Implement Rep 2019;17:793-984.

20 Carroll N, Sadowski A, Laila A, et al. The impact of COVID-19 on health behavior, stress, financial and food security among middle to high income Canadian families with young children. Nutrients 2020;12. doi:10.3390/nu12082352. [Epub ahead of print: 07 Aug 2020].

21 Bidad N, Barnes N, Griffiths C, et al. Understanding patients' perceptions of asthma control: a qualitative study. Eur Respir J 2018;51. doi:10.1183/13993003.01346-2017. [Epub ahead of print: 2806 2018].

22 Farnesi B-C, Ducharme FM, Blais L, et al. Guided asthma selfmanagement or patient self-adjustment? using patients' narratives to better understand adherence to asthma treatment. Patient Prefer Adherence 2019;13:587-97. 
23 Poland BD. Transcription quality. In: Gubrium JF, Holstein JA, eds. Handbook of interview research. Thousand Oaks, CA: Sage Publications, 2002: 629-50.

24 Nathan RA, Sorkness CA, Kosinski M, et al. Development of the asthma control test: a survey for assessing asthma control. J Allergy Clin Immunol 2004;113:59-65.

25 Patton MQ. Qualitative research and evaluation methods. 3rd ED. Newbury Park, CA: Sage, 2002.

26 Kvale S, Brinkmann S. Interviews: learning the craft of qualitative research interviewing. Los Angeles, CA: Sage, 2009.

27 Braun V, Clarke V. Using thematic analysis in psychology. Qual Res Psychol 2006;3:77-101.

28 Pope C, Ziebland S, Mays N. Qualitative research in health care. Analysing qualitative data. BMJ 2000;320:114-6.

29 Ritchie J, Spencer L. Qualitative data analysis for applied policy research. In: Bryman A, ed. Analyzing qualitative data. London and New York: Routledge, 1994: 173-94.

30 Glaser B, Strauss A. The discovery of grounded theory: strategies for qualitative research. New Brunswick: Aldine Transaction, 1999.

31 Horne R, Price D, Cleland J, et al. Can asthma control be improved by understanding the patient's perspective? BMC Pulm Med 2007;7:8

32 Gautier C, Charpin D. Environmental triggers and avoidance in the management of asthma. J Asthma Allergy 2017;10:47-56.

33 Pelaia G, Vatrella A, Gallelli L, et al. Respiratory infections and asthma. Respir Med 2006:100:775-84.

34 Nnodum BN, McCormack MC, Putcha N, et al. Impact of physical activity on reporting of childhood asthma symptoms. Lung 2017:195:693-8.
35 Dales R, Chen L, Frescura AM, et al. Acute effects of outdoor air pollution on forced expiratory volume in $1 \mathrm{~S}$ : a panel study of schoolchildren with asthma. Eur Respir J 2009;34:316-23.

36 Ahmed SAKS, Ajisola M, Azeem K, et al. Impact of the societal response to COVID-19 on access to healthcare for non-COVID-19 health issues in slum communities of Bangladesh, Kenya, Nigeria and Pakistan: results of pre-COVID and COVID-19 lockdown stakeholder engagements. BMJ Glob Health 2020;5:e003042.

37 Shaker MS, Oppenheimer J, Grayson M, et al. COVID-19: pandemic contingency planning for the allergy and immunology clinic. J Allergy Clin Immunol Pract 2020;8:1477-88.

38 Bengtson LGS, DePietro M, McPheeters J, et al. Real-World outcomes in patients with chronic obstructive pulmonary disease initiating long-acting mono bronchodilator therapy. Ther Adv Respir Dis 2018;12:1753466618772750.

39 Engelkes M, Janssens HM, de Jongste JC, et al. Medication adherence and the risk of severe asthma exacerbations: a systematic review. Eur Respir J 2015;45:396-407.

40 Centers for Disease Control and Prevention (U.S.). People with moderate to severe asthma, 2021. Available: https://www.cdc.gov/ coronavirus/2019-ncov/need-extra-precautions/asthma.html

41 British Thoracic Society, Scottish Intercollegiate Guideline Network. British guideline on the management of asthma, 2019. Available: https://www.sign.ac.uk/our-guidelines/british-guideline-on-themanagement-of-asthma/

42 Hodkinson A, Bower P, Grigoroglou C, et al. Self-Management interventions to reduce healthcare use and improve quality of life among patients with asthma: systematic review and network metaanalysis. BMJ 2020;370:m2521. 